\title{
Implicações do Programa de Formação-Ação em Escolas Criativas na prática pedagógica de uma escola do campo
}

\author{
Implications of the Formation-Action Program in Creative Schools for the \\ teaching Practices of a rural school \\ Implicaciones del Programa de Formación-Acción en Escuelas Creativas en la \\ práctica pedagógica de una escuela rural
}

\author{
Aline Lima da Rocha Almeida ${ }^{1}$ \\ Marlene Zwierewicz ${ }^{2}$
}

Recebido em 21/01/2019; revisado e aprovado em 16/12/2019; aceito em 13/01/2020

DOI: http://dx.doi.org/10.20435/inter.v22i1.2359

\begin{abstract}
Resumo: As escolas do campo apresentam características peculiares, requisitando práticas pedagógicas que se aproximem do perfil dos estudantes e considerem a realidade das comunidades em que se inserem. A fim de priorizar essa perspectiva, este estudo teve como objetivo avaliar o potencial de uma ação extensionista, constituída por um programa de formação-ação, para a transformação da prática pedagógica e para o atendimento das necessidades formativas dos docentes de uma escola do campo de Santa Catarina. A formação foi acompanhada por uma pesquisa-ação, e a coleta de dados foi realizada por meio de dois questionários aplicados aos oito docentes que atuavam na escola. Os resultados indicam que a iniciativa contribuiu para redimensionar o planejamento e para estimular o trabalho colaborativo, a articulação do conteúdo curricular com a realidade do campo, o comprometimento e o interesse dos estudantes, a ampliação de diálogos fundamentados na teoria, a criatividade individual e coletiva e o protagonismo dos estudantes.

Palavras-chave: escola do campo; formação docente; transdisciplinaridade; ecoformação.

Abstract: Rural schools have distinct features that promote teaching practices that take into account the students' profiles and the reality of their communities. Considering this perspective, the present study evaluates the potential of an extension activity constituted by a program of formation-action for transforming teaching practices and addressing the needs of the teachers' academic development in a rural school in the state of Santa Catarina, in Southern Brazil. The formation was followed by a research-action and the data was collected after applying two questionnaires to the eight teachers in the institution. Results indicate that the initiative contributed to reshaping and fostering collaborative work, associating content and rural contexts, engaging the students, continuing dialogues backed by theory, to individual and group creativity, and students' active participation.
\end{abstract}

Keywords: rural school; teacher formation; transdisciplinarity; eco-formation.

Resumen: Las escuelas rurales presentan características peculiares, ya que suscitan prácticas pedagógicas que se aproximan al perfil de los estudiantes y que, a su vez, consideran la realidad de las comunidades en las que están introducidos. Dándole prioridad a esa perspectiva, este estudio tuvo como objetivo evaluar el potencial de una acción de extensión, constituida por un programa de formación-acción para transformar la práctica pedagógica y atender las necesidades formativas de los docentes de una escuela rural de Santa Catarina, en el Sur de Brasil. La formación estuvo acompañada de una investigación-acción, y los datos se recolectaron tras aplicar dos cuestionarios a los ocho docentes de la institución. Los resultados indican que la iniciativa contribuyó para redimensionar la planificación y estimular el trabajo colaborativo, articular el contenido curricular con la realidad del campo, activar el compromiso e interés de los estudiantes, ampliar diálogos fundamentados en teoría, para la creatividad individual y colectiva y, finalmente, para el protagonismo de los estudiantes.

Palabras claves: escuela rural; formación docente; transdisciplinariedad; ecoformación.

\footnotetext{
${ }^{1}$ Escola Municipal de Educação Básica (EMEB) Rodolfo Nickel, Caçador, Santa Catarina, Brasil.

${ }^{2}$ Universidade Alto Vale do Rio do Peixe (UNIARP), Caçador, Santa Catarina, Brasil.
} 


\section{INTRODUÇÃO}

Com os avanços tecnológicos e o processo de globalização, impulsionados especialmente a partir da década de 1990, passaram-se a ser vivenciadas transformações vultosas que afetam a realidade global e se capilarizam localmente. Entre os problemas que permeiam esse processo de mutação acelerada, Morin (2015) destaca o desregramento ecológico, a exclusão social, a exploração sem limites dos recursos naturais, a busca desumanizante por lucro e a ampliação das desigualdades sociais.

Problemas como esses afetam toda a sociedade, chegando também às escolas do campo, indicando a emergência de um redirecionamento das práticas pedagógicas. Notadamente, nesse contexto, evidencia-se a necessidade de superar a visão míope que transpassou as políticas públicas para esses lugares, restringindo os problemas enfrentados pelas populações distantes dos centros urbanos às condições geográficas e ao número reduzido de habitantes das comunidades (BRASIL, 2007).

A Escola Municipal de Educação Básica (EMEB) Rodolfo Nickel, vinculada à Rede Municipal de Ensino de Caçador (Santa Catarina), é uma das instituições permeadas por essa necessidade. Os estudantes por ela atendidos na Educação Infantil e nos anos iniciais do Ensino Fundamental vivenciam, diariamente, a realidade de uma comunidade com grande potencial agrícola, mas com dificuldades de acesso, além de outras demandas a serem consideradas na transição de um ensino descontextualizado para uma perspectiva transdisciplinar e ecoformadora.

A oportunidade de desenvolver uma ação extensionista a fim de atender a essas demandas surgiu por meio do Programa de Mestrado Profissional em Educação Básica (PPGEB) da Universidade Alto Vale do Rio do Peixe (UNIARP). A aplicabilidade da proposta viabilizou-se por priorizar a pesquisa com intervenção (UNIARP, 2018) e, também, pela parceria entre a instituição e a Secretaria Municipal da Educação de Caçador.

A iniciativa teve como pretensão oferecer novas possibilidades aos docentes, para sua atuação tanto em sala de aula como na interação com a comunidade. Por isso, a formação procurou estimular que os processos de ensino e de aprendizagem aproximassem o currículo escolar da realidade local e das demandas globais, por meio da articulação teórico-prática e da religação de saberes.

A sistematização das bases epistemológicas e da proposta formativa elucida a ação extensionista. Já os resultados apresentados neste artigo derivam da pesquisa, cujo objetivo foi avaliar o potencial do Programa de Formação-Ação em Escolas Criativas, estruturado para proporcionar transformações na prática pedagógica e no atendimento das necessidades formativas dos docentes da EMEB Rodolfo Nickel.

A escola está situada no Assentamento Hermínio Gonçalves dos Santos, interior do município de Caçador. No momento da pesquisa, atendia 65 estudantes da comunidade local. O quadro de profissionais era formado por uma Especialista em Assuntos Educacionais (EAE), responsável pelas demandas pedagógicas e administrativas da escola, e por oito docentes, três de turma e cinco das disciplinas de Arte, Educação Física, Filosofia, Inglês e Informática.

O estudo organizou-se em cinco etapas, que priorizaram a pesquisa-ação e a abordagem qualitativa. Tais etapas definiram-se com o intuito de atender aos objetivos específicos, entre eles: caracterizar o perfil docente e suas necessidades formativas; analisar programas de formação de docentes com resultados publicados e contribuições para a intervenção local; conhecer a percepção dos docentes sobre as atividades formativas; e sistematizar as ações planejadas no 
projeto de intervenção, elaborado pelos docentes durante a formação e desenvolvido na escola vinculada à pesquisa.

Participaram do estudo os oito docentes atuantes na escola e 18 dos 65 estudantes implicados no projeto de intervenção, além de estudantes que visitaram a escola e uma profissional da Secretaria de Educação de Caçador, a qual acompanhou a formação. Neste artigo, contudo, sistematizam-se somente dados coletados junto aos docentes mediante a aplicação de dois questionários: o primeiro avaliou o perfil desses profissionais e suas necessidades formativas; o segundo, os resultados do programa na percepção dos mesmos.

Destaca-se o fato de o projeto de pesquisa ter sido aprovado pelo Comitê de Ética e que, na coleta de dados, utilizaram-se quatro documentos adicionais: Declaração de Ciência e Concordância das instituições envolvidas, Termo de Consentimento Livre e Esclarecido (TCLE) para menores de idade, TCLE para docentes e Termo de Autorização de Uso de Imagem.

Ao oferecer aos docentes de uma escola do campo a possibilidade de participar de uma formação - cuja metodologia se constituiu pelos Projetos Criativos Ecoformadores (PCEs) ${ }^{3}$, ou seja, uma alternativa comprometida com transdisciplinaridade e ecoformação -, esperava-se que a participação no programa refletisse diretamente na prática pedagógica desempenhada na escola implicada. Pretendia-se, nesse processo, superar estereótipos formativos que, de acordo com Gatti, Barreto e André (2011), são desenvolvidos de maneira descontextualizada da escola, priorizando uma formação transmissiva e centrada em palestras, seminários, oficinas e cursos rápidos.

\section{DA FORMAÇÃO DESCONTEXTUALIZADA À FORMAÇÃO-AÇÃO NORTEADA POR TRANSDISCIPLINARIDADE E ECOFORMAÇÃO}

Vive-se em uma realidade "[...] caracterizada pelo fenômeno da globalização e pelas tensões e pressões que este fenômeno e os seus processos exercem sobre cada Estado-Nação [...]". Essa condição, acelerada por uma política neoliberal, fortalece um modelo social regido por imperativos econômicos, acentuando medidas que se revelam em mecanismos de distribuição ínfima de renda (ABREU, 2017, p. 2).

As consequências que se acentuam por essas premissas neoliberais são múltiplas e afetam todas as dimensões da sociedade (SILVA, 2014). Em decorrência disso, a educação se transforma em um produto a ser consumido e sua eficácia se amplia à medida que colabora para a distribuição do capital cultural, de acordo com os lugares sociais em que cada pessoa está inserida (BOURDIEU, 2001).

Diante dessa realidade, é essencial que as instituições de ensino transformem suas práticas e, da mesma forma que são influenciadas pela sociedade, evidenciem seu potencial de influência, colaborando tanto para dar visibilidade à realidade local e global como para minimizar a exclusão em todas as suas formas de manifestação. Como o docente é um dos agentes fulcrais para efetivar mudanças na realidade escolar e no seu entorno, sua atuação envolve uma gama extensa e complexa de situações, exigindo tanto uma sólida formação inicial como uma formação continuada compatível com as demandas da realidade atual.

Além disso, Aranha (2006) defende que a atuação no âmbito educacional deve se caracterizar pela presença de docentes reflexivos e transformadores. Dessa forma, podem

\footnotetext{
${ }^{3}$ A metodologia dos Projetos Criativos Ecoformadores (PCEs) foi criada por Torre e Zwierewicz (2009), sendo utilizada tanto como base para organização da ação extensionista, ou seja, do programa de formação oferecido aos docentes da EMEB Rodolfo Nickel, como para as práticas pedagógicas desenvolvidas por eles em sala de aula.
} 
problematizar suas escolhas educativas e compreender as consequências dessas nos processos de ensino e de aprendizagem, tal como indica a Universidade de Borås (2012), da Suécia, quando define as competências dos docentes nela atuantes.

Para isso, é urgente refletir sobre a problemática educacional em sua totalidade, tomando distanciamento de discursos romantizados e que, muitas vezes, justificam a formação dos docentes com iniciativas descontextualizadas (MORAES, 2011). Assim, seminários ou palestras dissociadas da prática efetiva dos docentes não são suficientes para suprir as necessidades que esses encontram em uma realidade em constante transformação. Nóvoa (2001) reforça que ofertar atividades isoladamente pouco acrescenta a tais profissionais. Defende, ainda, que a formação deve se dar no âmbito coletivo, ou seja, junto à transformação da escola, pois nela acontecem as transformações de docentes e estudantes.

Gatti, Barreto e André (2011) afirmam também ser necessário refletir sobre os referenciais de formação continuada que vêm sendo implantados, especialmente quando desenvolvidos de maneira descontextualizada da realidade escolar, priorizando ainda a formação transmissiva, centrada em palestras, seminários, oficinas e cursos rápidos.

Morin (2009), por sua vez, defende que não é viável transformar uma instituição sem transformar, simultaneamente, as mentes. Da mesma forma, não é viável transformar as mentes sem transformar, simultaneamente, as instituições. Por isso, é necessário pensar em uma formação contextualizada e que priorize o desenvolvimento de encontros no próprio no contexto escolar, estimulando que as mudanças se efetivem em ação.

Nóvoa (2002) propõe, então, uma prática de reflexão que transforme a formação em um espaço de discussão, para que as contribuições singulares adquiram visibilidade e façam parte de um processo colaborativo de valorização contínua. Essa condição oportuniza o saber analisar e o saber analisar-se para buscar, no coletivo, a superação de práticas pedagógicas que não respondem às demandas da realidade educacional.

Com o intuito de atender a essa perspectiva, a transdisciplinaridade e a ecoformação foram os conceitos norteadores da elaboração do Programa de Formação-Ação em Escolas Criativas. Esses conceitos convergem com o paradigma ecossistêmico e com o pensamento complexo, favorecendo que os docentes aproximem o currículo da realidade dos estudantes e ampliem a pertinência do ensino.

O conceito de transdisciplinaridade surgiu publicamente na França, em 1970, mencionado por Jean Piaget. No entanto, difundiu-se por Nicolescu (2005; 2014), que o define como aquilo que está entre as disciplinas, através e além delas.

A transdisciplinaridade é compreendida também como a busca pelo sentido da vida, permeada por relações entre os diversos saberes e resultante de uma democracia cognitiva (SANTOS, 2009). Tal democracia suscita a religação dos saberes (GONZÁLEZ VELASCO, 2018) e, portanto, das disciplinas, e dessas com a realidade.

A inserção de uma proposta transdisciplinar em sala de aula sugere a "[...] superação da mentalidade fragmentária, incentivando conexões e criando uma visão contextualizada do conhecimento, da vida e do mundo" (SANTOS, 2005, p. 2-3). Nesse processo, a transdisciplinaridade repousa, inicialmente, sobre as disciplinas, mas as transcende, fortalecendo "[...] a construção de uma nova epistemologia capaz de resgatar a multidimensionalidade do sujeito, compreendido a partir de uma ontologia complexa" (RIBEIRO; MORAES, 2014, p. 244), condição imprescindível para o reencontro consigo, com o outro e com a natureza. 
Nesse reencontro, a transdisciplinaridade se articula à ecoformação, que é considerada uma maneira sintética, integradora e sustentável de entender a ação formativa, sempre em relação ao sujeito, à sociedade e à natureza (TORRE, 2009). Sua intenção é contribuir para "[...] estabelecer as premissas teóricas das unidades ecológicas de base que religam o homem à natureza [...]", transformando-se em "[...] um processo mediador da relação do homem com seu ambiente social e natural" (SILVA, 2008, p. 97).

Ao representar mais do que o diálogo entre os sistemas discursivos, a ecoformação "[...] parece ser, ela mesma, [...] um diálogo da humanidade com seu ambiente social e natural nos termos do que Morin chama de compreender a humanidade da humanidade" (SILVA, 2008, p. 102). Nesse processo, impulsiona reflexões e ações que vão além da transmissão de conhecimentos historicamente acumulados, ou mesmo da visão crítica em relação a eles.

\section{PERFIL DOS DOCENTES DA EMEB RODOLFO NICKEL E SUAS NECESSIDADES FORMATIVAS}

Para caracterizar o perfil dos docentes da EMEB Rodolfo Nickel e suas necessidades formativas, coletaram-se dados por meio da aplicação de um questionário elaborado e validado para essa finalidade. Aplicou-se o instrumento aos oito docentes que atuavam na instituição no final do mês de fevereiro de 2018, antes do início dos encontros formativos.

Dos oito docentes, predominou o sexo feminino, com sete mulheres e um homem. A predominância feminina na Educação Básica vem sendo evidenciada em outros estudos, entre os quais, Cardoso et al. (2011) e Magno et al. (2012). Em relação à formação, constatou-se que um docente estava concluindo a graduação, cinco tinham graduação completa e dois haviam feito pós-graduação lato sensu.

Entre os oito docentes, sete participaram de formações continuadas nos últimos dois anos. Ao serem questionados sobre a aplicação dos conhecimentos trabalhados no decorrer das formações, três afirmaram que os utilizavam eventualmente em sala de aula e quatro utilizavam quase sempre. Esse resultado converge com as preocupações de Nóvoa et al. (1992), quando afirmam que a formação deve ocorrer no coletivo, não antes, nem depois, mas junto à transformação da escola.

Quanto às necessidades formativas, questionaram-se os docentes sobre os maiores desafios na sala de aula, temas de interesse para formações futuras e melhorias necessárias à instituição. A perspectiva era de que as respostas contribuíssem para a elaboração do programa de formação-ação, atendendo, dessa forma, a suas necessidades formativas.

Suas respostas indicaram que, dentre os desafios de atuar na escola do campo investigada, estavam: a pouca participação dos pais nas atividades escolares; a falta de interesse dos estudantes, além da falta de domínio de alguns conteúdos prévios indispensáveis à sequência dos estudos; e, também, as condições de infraestrutura da escola. Em relação aos temas para formações, os docentes sugeriram planejamento, metodologia de ensino, Projeto PolíticoPedagógico (PPP) e inclusão.

Parte substancial das necessidades apontadas pelos docentes convergiu com especificidades consideradas no Programa de Formação-Ação em Escolas Criativas desenvolvido em outras escolas (ZWIEREWICZ, 2017; ZWIEREWICZ et al., 2017). Isso facilitou a adaptação do programa, favorecendo a estruturação de uma proposta que considerasse a realidade local. 


\section{O PROGRAMA DE FORMAÇÃO-AÇÃO EM ESCOLAS CRIATIVAS: PERTINÊNCIA E EMPATIA NOS PROCESSOS DE ENSINO E DE APRENDIZAGEM}

A partir de análises do Programa de Formação-Ação em Escolas Criativas, conforme desenvolvido em outros contextos, e também da caracterização do perfil dos docentes e da identificação de suas necessidades formativas, possibilitou-se estruturar um programa específico para a EMEB Rodolfo Nickel. Esse programa teve como objetivo superar os desafios da instituição, valorizando, igualmente, seus potenciais.

Pautada nos princípios da transdisciplinaridade e da ecoformação, contemplando também as indicações da Base Nacional Comum Curricular (BNCC) (BRASIL, 2017), das Diretrizes Curriculares da Educação Infantil da Associação dos Municípios do Alto Vale do Rio do Peixe (AMARP, 2016) e outros documentos norteadores da educação em Caçador, organizou-se a proposta em cinco etapas, totalizando uma carga horária de 24 horas. Na realização das etapas, procurou-se mobilizar os docentes para consolidarem a formação de modo que se traduzisse, de fato, pela ação.

Não se tratava, portanto, de uma formação tradicional, pois, enquanto contribuía com o aprofundamento da concepção pedagógica, priorizava uma metodologia que estimulava a aplicação na escola do proposto coletivamente pelos docentes durante a formação. Dessa forma, pretendia-se reduzir os índices elevados de docentes que utilizavam eventualmente o que era trabalhado nas formações, como foi detectado por suas respostas ao questionário aplicado.

Realizaram-se as quatro primeiras etapas após o horário das aulas na Secretaria Municipal de Educação (SME) de Caçador. A etapa de encerramento ocorreu na escola e no Centro Comunitário, já que ambos os edifícios são próximos, e as atividades exigiam um espaço maior que o das salas de aula.

- Etapas da conexão e da projeção: conforme a proposta original do Programa de Formação-Ação em Escolas Criativas (ZWIEREWICZ et al., 2017), a etapa da conexão se dá no início do programa e objetiva impactar os participantes, utilizando estratégias a fim de situarem suas práticas, identificarem e valorizarem as inovações realizadas antes do início da formação, bem como os desafios a serem enfrentados, além de trabalharem as bases teóricas norteadoras do programa e as possibilidades metodológicas e avaliativas. A etapa da projeção, por sua vez, prevê planejamentos, objetivando reduzir a distância entre o realizado e o desejado e, por isso, envolve a elaboração de Projetos Criativos Ecoformadores (PCEs), metodologia criada por Torre e Zwierewicz (2009), que possibilita dinamizar, em sala de aula, as perspectivas da transdisciplinaridade e da ecoformação.

No caso específico da formação dos docentes da EMEB Rodolfo Nickel, agruparam-se essas duas etapas ocorridas no início do mês de março de 2018. Elas constituíram momentos essenciais para conectar a proposta às reais necessidades dos docentes, e sua dinamização se deu por meio de um planejamento colaborativo e pertinente.

Considerando o epítome, ou seja, o primeiro organizador conceitual do PCE, as etapas iniciaram com uma dinâmica, cujo objetivo foi refletir sobre as práticas pedagógicas ainda presentes na escola pesquisada e na realidade da educação brasileira. Após a dinâmica, apresentou-se a proposta preliminar do programa, justificando a escolha de seu subtítulo Pertinência e empatia nos processos de ensino e aprendizagem. O subtítulo do programa, acolhido pela equipe, procurava manter relação com as especificidades da escola do campo pesquisada, 
detectadas por meio da aplicação do primeiro questionário, quando os docentes indicaram preocupações com o planejamento e a metodologia de ensino.

Na ocasião, discutiram-se o paradigma e os conceitos que permeavam a proposta formativa. Partiu-se do paradigma ecossistêmico e do pensamento complexo para que, na sequência, fossem aprofundadas as discussões sobre a transdisciplinaridade e sobre a ecoformação.

Nesse processo, resgataram-se práticas enraizadas pelo paradigma positivista para que os docentes pudessem refletir sobre a escola atual. Eles também foram questionados sobre o que pensavam enquanto dialogavam sobre a escola na qual atuavam.

Na interlocução, surgiram potencialidades e demandas relacionadas à EMEB Rodolfo Nickel, às instituições que a apoiam, aos estudantes e à comunidade. Entre as potencialidades e as demandas, identificaram-se: o cultivo diversificado de alimentos, o uso acentuado de agrotóxicos e o acesso precário à comunidade.

A partir do que se identificou, os docentes analisaram a proposta curricular do município, selecionando conteúdos que poderiam se relacionar a tais potencialidades e demandas tais como o sistema monetário, os meios de transporte, aspectos históricos da comunidade, cartografia, alimentação, cultivo, higiene e solo. Ao indicar esses conteúdos, os docentes pretendiam que esses fizessem sentido aos estudantes, ampliando a pertinência do ensino.

Para potencializar essa conexão, decidiram dar continuidade à exploração do livro de literatura infantil intitulado Felpo Filva, de Eva Furnari, que se havia iniciado no ano anterior e que possibilitaria o estudo de diversos gêneros textuais. Como é um conteúdo relevante para ser abordado em todas as turmas, optou-se pela inclusão da obra no subtítulo do PCE que seria desenvolvido na escola no decorrer da formação: Projeto Criativo Ecoformador: as aventuras de Felpo Filva na escola do campo.

Ao final do encontro, os docentes acordaram em elaborar e aplicar atividades relacionadas aos conteúdos evidenciados por eles, relembrando sua articulação com as demandas e as potencialidades identificadas na etapa formativa. Definiu-se também que, na etapa seguinte, compartilhariam ações implementadas na escola.

Como toda a escola trabalharia com o mesmo PCE, cada docente buscaria a articulação de sua área de conhecimento com as demais, bem como a interação da turma em que atuava com as outras turmas. Dessa forma, pretendiam-se ampliar possibilidades em que os estudantes aprendessem com seus pares, com estudantes de outras faixas etárias e com outros docentes, estimulando-se, do mesmo modo, a interação junto à comunidade e às outras instituições de apoio à escola.

- Etapa da interação: esta etapa teve como foco estimular a socialização das ações desenvolvidas a partir da formação, iniciando-se com a rememoração dos conceitos norteadores do encontro anterior para conectar a teoria às práticas que seriam compartilhadas na sequência.

Atendendo ao que se propuseram no encontro anterior, os docentes passaram a socializar as atividades desenvolvidas a partir das primeiras etapas. Observou-se nos relatos que, em alguns casos, os docentes foram muito além do que se haviam proposto, evidenciando o quanto consideraram os desafios das etapas iniciais. As falas de alguns docentes, registradas a seguir e acompanhadas por um código de diferenciação para cada profissional, caracterizaram tanto o compromisso assumido por eles quanto como isso repercutiu em sala de aula.

Ao relatar as experiências com os gêneros textuais carta e contos de fadas, o professor designado como P1 afirmou que as crianças se envolveram muito e estavam curiosas em relação ao que trabalhariam. P2, por sua vez, comentou: "[...] todos participaram ativamente da atividade 
proposta e com muita empolgação, sendo um dia muito divertido [...]", referindo-se à gincana de cooperação e à brincadeira de caça aos pinhões, duas atividades previstas para articular o conteúdo curricular à realidade da comunidade, priorizando, além da interdisciplinaridade, práticas transdisciplinares.

O docente P8 compartilhou uma atividade sobre as partes do corpo e sua higiene, destacando como trabalhou com o vocabulário em inglês. Na socialização, foi perceptível a articulação da língua estrangeira com o objetivo do projeto.

Durante o encontro, complementaram-se continuamente ações vinculadas ao PCE, dando visibilidade às atividades que já haviam sido trabalhadas e o planejamento de ações para o período subsequente. Além disso, discutiu-se o artigo Escolas Criativas: experiências transformadoras potencializadas na interação do Ensino Superior com a Educação Básica (ZWIEREWICZ et al. 2016), que havia sido encaminhado aos docentes com antecedência. Tal capítulo contempla experiências criativas e inovadoras que poderiam ser exemplos para a continuidade, cada vez mais efetiva, da transformação das práticas pedagógicas da escola pesquisada.

-Etapa do fortalecimento: esta teve como pretensão aprofundar conhecimentos teóricos, articulando-os a possibilidades práticas. Ela aconteceu em dois encontros: um ao final de julho, quando o primeiro semestre estava sendo concluído; outro, em setembro.

No primeiro encontro, trabalhou-se um vídeo sobre tendências pedagógicas. O propósito era refletir sobre como muitas escolas ainda estão arraigadas ao paradigma positivista, além de observar o quanto a equipe de docentes da escola pesquisada estava avançando no sentido de priorizar uma perspectiva transdisciplinar e ecoformadora.

Apresentou-se, também, a versão atualizada do Projeto Criativo Ecoformador: as aventuras de Felpo Filva na escola do campo, com uma rememoração, por meio de imagens, do que se havia trabalhado até o momento na escola. No encontro, aprofundou-se o conceito de Escolas Criativas por meio dos estudos de Torre (2013). Retomaram-se, ainda, os organizadores conceituais dos PCEs, descritos por Torre e Zwierewicz (2009).

Na sequência, os docentes receberam a tarefa de elencar atividades possíveis para suas turmas, especificamente, e para a escola em geral, visando à ampliação da articulação entre os conteúdos curriculares e a realidade dos estudantes. Essa foi uma forma de superar alguns obstáculos, como os caracterizados na seguinte fala de P1: "[...] eu tenho muita dificuldade em conectar a matemática no PCE, apesar de saber que a matemática está em tudo".

Enquanto pensavam em cada área e turma, identificavam também possibilidades de envolver toda a escola. Essa atividade realizou-se por meio da "dinâmica da pizza". Nela, cada docente recebeu uma "fatia" de papel para registrar possibilidades específicas e, ao juntá-la com as outras "fatias", evidenciava-se o que poderia ser desenvolvido em conjunto.

P1, que comentara sobre a dificuldade em conectar a área de matemática ao PCE, propôs um trabalho com o sistema monetário por meio da simulação de um mercado, além de uma vivência com a comercialização de itens produzidos pela comunidade, a ser feita no Dia da Família na Escola, que aconteceria em agosto.

A docente de Arte propôs, então, a criação de um food truck para que os estudantes pudessem divulgar os alimentos saudáveis produzidos pela comunidade, evidenciando uma perspectiva tanto transdisciplinar como ecoformadora. A mesma docente era regente das turmas de 4 으 e 5 음 anos e se propôs a trabalhar com o solo e o cultivo de plantas, explorando fração e o gênero textual paródia ao relacionar os conteúdos ao tema alimentação saudável. 
A docente da turma de Educação Infantil apresentou a possibilidade de explorar o curtametragem $O$ menino e a caixa, de Temujin Doran, para, a seguir, desenvolver junto às crianças uma experiência com caixas, vinculando-a ao eixo de imaginação e de interação da Proposta Curricular de Educação Infantil (AMARP, 2016).

Dando continuidade às apresentações, a docente do 1 으 ano elencou a classificação de plantas como um conteúdo para estudar seus tamanhos, cheiros, utilidades. Ela se ofereceu, também, para solicitar às crianças que coletassem, em suas casas, sementes e mudas para cultivar na escola, como uma forma de valorizar a realidade local.

A professora de Arte, de modo igual, apresentou uma proposta com o uso de tintas produzidas a partir de alimentos cultivados pela comunidade. Em cada turma, utilizou-se uma técnica diferente e, ao final do processo, socializaram-se as experiências com as demais turmas para que novos conhecimentos fossem acessados.

A docente de Informática, por sua vez, disponibilizou um material rico para o trabalho com sementes, envolvendo desde a germinação até o desenvolvimento da planta. Além disso, destacou as possibilidades que as pesquisas oferecem e relatou que as turmas do 3음 a음 ano já apresentavam bastante autonomia no uso do computador e dos netbooks disponibilizados aos estudantes, afirmando que poderiam ser estimulados a realizar diversos estudos sobre o tema. Na sequência, os docentes refletiram, então, sobre a relevância das tecnologias digitais e como essas podem estimular uma visão global se utilizadas conscientemente, fortalecendo o viés ecoformador quando indicaram a relevância do compromisso com o bem-estar individual, social e ambiental.

Ainda vinculado à etapa de fortalecimento, realizou-se o quarto encontro de formação. Devido à parceria da SME com as escolas para a elaboração de questões vinculadas à avaliação externa, abordaram-se os descritores da Prova Brasil (BRASIL, 2008) e se compararam aos da Rede Municipal de Ensino de Caçador, elaborados a partir das competências e habilidades previstas na Base Nacional Comum Curricular (BNCC) (BRASIL, 2017).

O quarto encontro teve início com a projeção do vídeo Sementes germinando, para que os docentes refletissem sobre as possibilidades criadas na formação e a partir dela. Especificamente, a atividade objetivava contribuir com alternativas voltadas à leitura e à interpretação, aspectos valorizados na Prova Brasil. Por isso, ressaltou-se a importância de o docente prever, em seu planejamento, diferentes estratégias que as estimulassem, com a finalidade de os estudantes se apropriarem das especificidades desse tipo de avaliação.

Esse encontro foi marcado por profundas reflexões acerca das práticas pedagógicas e da relação dessas com as autoavaliações e as avaliações dos estudantes. Pelo fato de estarem trabalhando com uma metodologia que estimulava a produção no lugar da reprodução, ficou mais clara a visualização de questões avaliativas que priorizassem a interpretação e a resolução de problemas.

- Etapa da polinização: nesta etapa, promoveu-se a divulgação dos resultados dos PCEs. Este foi considerado um momento para valorizar as escolas, os profissionais, os estudantes, a comunidade e suas iniciativas, contribuindo, também, para que outros contextos pudessem ressignificar suas práticas a partir daquilo que foi compartilhado, conforme evidenciam Zwierewicz et al. (2017).

A etapa coincidiu com o quinto e último encontro, que aconteceu no contexto de atuação dos docentes e culminou com a primeira Mostra do Conhecimento da escola. No evento, apresentaram-se todas as etapas do Projeto Criativo Ecoformador: as aventuras de Felpo Filva na escola do campo. 
Na oportunidade, a escola recebeu a visita dos familiares das crianças, da extensionista social da Empresa de Pesquisa Agropecuária e Extensão Rural de Santa Catarina (EPAGRI), da secretária de Educação e de outros profissionais da Secretaria de Educação de Caçador, bem como de estudantes e de docentes de duas escolas da cidade. Ao todo, cinco turmas visitaram a escola, totalizando 112 estudantes e 12 docentes externos.

Na organização do evento, dividiram-se os estudantes da EMEB Rodolfo Nickel em sete equipes. Cada grupo ficou responsável por apresentar uma etapa do PCE, orientar os visitantes e entregar lembranças vinculadas à realidade local. Todas as etapas foram elaboradas e desenvolvidas ao longo do ano pelas turmas, e a apresentação dos resultados caracterizou um momento de valorização e de empoderamento impulsionado por um ensino transdisciplinar e ecoformador.

\section{A PERCEPÇÃO DOS DOCENTES SOBRE O PROGRAMA DE FORMAÇÃO-AÇÃO EM ESCOLAS CRIATIVAS}

Para conhecer a percepção dos docentes sobre a influência do Programa de FormaçãoAção em Escolas Criativas, tanto em sua prática pedagógica quanto no atendimento de suas necessidades formativas, aplicou-se um questionário ao final do processo. As perguntas direcionaram-se ao planejamento, à articulação entre teoria e prática, ao trabalho colaborativo e a outros aspectos contextualizados adiante.

Em relação à influência do programa de formação-ação no planejamento, a maioria dos docentes respondeu que ele interferiu diretamente na sua organização. Como exemplo, destacase o registro de P5: "Sim, a formação continuada, onde foram discutidas ideias e planejamentos relacionados ao projeto do Felpo Filva, foi muito enriquecedora; conseguimos nos apropriar de novos conhecimentos teóricos fundamentais para nosso desenvolvimento como professor".

Essa influência, igualmente, ocorreu com os docentes que já tinham adotado a metodologia de projetos em sala de aula, como se pode observar no seguinte registro:

A formação na verdade me trouxe uma clareza em relação ao que eu já estava fazendo, um enriquecimento de vocabulário, com conceitos como ecoformação e transdisciplinaridade, além de atividades que já faziam parte do nosso trabalho, mas que precisavam de uma orientação. (P1).

Em relação à ampliação do trabalho colaborativo, os docentes ressaltaram as parcerias e a conexão entre as atividades, conforme pode ser observado no dois registros seguintes: "Sim, foi uma parceria que envolveu os alunos, os docentes, além dos pais e demais funcionários da escola; juntos desenvolvemos atividades que foram vinculadas ao dia a dia da comunidade [...]" (P3); "Acredito que houve sim colaboração entre os docentes, pois tentou-se fazer uma teia de atividades, uma ligando com a outra, isso a partir de conversas e planejamento de que atividades realizar" (P8).

Quanto à influência do projeto na articulação do conteúdo curricular com a realidade do campo, enfatizou-se o envolvimento das vivências dos estudantes com estímulo à autonomia, ao respeito e à valorização do meio. Em decorrência disso, o ensino mostrou-se mais pertinente. Nesse sentido, P1 registrou que, ao desenvolver o projeto, os docentes não apenas procuraram priorizar atividades relacionadas ao meio e às vivências dos estudantes, mas que também ampliassem seus horizontes. Nesse processo, estimulou-se o desejo de "[...] conhecer, criar, 
sonhar e realizar trabalhos a fim de valorizar sua autonomia enquanto cidadão, respeitando seu meio e valorizando suas raízes" (P1).

P2, por sua vez, registrou que, em sala de aula, trabalharam-se os conteúdos de modo vinculado à realidade do campo, como em atividades sobre o sistema monetário e os gêneros textuais. Como exemplo, destacou a comercialização de produtos no food truck. Além disso, realizaram-se trocas de cartas, visita aos correios, jogos e brincadeiras sem finalidades competitivas, estimulando o espírito colaborativo.

Sobre a influência do programa de formação-ação na ampliação do interesse dos estudantes, todos os docentes foram unânimes em responder que o desenvolvimento do PCE foi favorável, ampliando, significativamente, o interesse de todos. Essa afirmação pode ser constatada pela fala de P3, ao registrar que o interesse dos estudantes ficou visível no decorrer do processo e, também, em momentos pontuais em que lançavam muitas perguntas. Para esse docente, a feira do conhecimento teve muita importância, pois assim destacou

[...] o quão valioso foi esse momento para todos os alunos e professores; foi expressamente notável o empenho, a transformação de conhecimento e aprendizagem, em especial a autonomia de cada um, no desenvolvimento, no comprometimento, na participação, dedicação; eles se empenharam muito. (P3).

A ampliação do interesse, de modo semelhante, evidenciou-se por P4, ao registrar que "Eles pareciam curiosos, ansiosos sobre o que viria a seguir, o que esperar das aulas, o que poderia e seria trabalhado". P2, por sua vez, destacou, como exemplo desse entusiasmo, o momento em que foram inseridos os conteúdos de localização geográfica e placas de sinalização. Segundo esse docente, um dos estudantes levou à escola uma imagem recortada de revista (com rios, matas, uma casa e pedras grandes) mostrando que naquele mapa se localizava a casa dele.

Sobre a influência do programa na transformação da prática pedagógica, P3 relatou que o aprendizado foi notável, envolvendo muitas atividades práticas, mediante as quais os estudantes "[...] se emocionaram, criaram, fizeram, confeccionaram, participaram ativamente de toda a aventura. Muitos avanços foram detectados, em especial a autonomia para se expressarem" (P3).

P2 destacou que "Foram observados diversos avanços, alguns muito notáveis, como o incentivo à leitura, o estímulo na criatividade e principalmente o despertar da curiosidade dos alunos aos assuntos propostos, além de todo o esforço e dedicação em produzir com vontade as atividades propostas". P8, por sua vez, registrou que os estudantes "[...] puderam perceber a importância do que eles viviam e como eles viviam (a cultura do plantar, colher), relacionando com o currículo apresentado na escola, em sala de aula e nas diferentes disciplinas".

Em relação à avaliação geral do programa de formação-ação, os docentes destacaram como pontos positivos:

- a articulação teórico-prática, aproximando os conteúdos da realidade;

- a oportunidade de diálogo fundamentado na teoria, estimulando uma nova visão sobre os processos de ensino e de aprendizagem;

- a possibilidade de desenvolver a criatividade individual e coletiva;

- o estímulo ao protagonismo dos estudantes;

- o trabalho colaborativo.

A P2 registrou, ainda, que observou "[...] uma melhora muito grande no processo de aprendizado dos alunos, bem como no crescimento profissional e no amplo leque de conteúdos e assuntos que o projeto proporcionou aos professores e alunos da escola". Para ele, além de 
se constituir como "[...] uma forma divertida e rica de se trabalhar, o PCE e toda a formação continuada proporcionaram aos docentes uma nova visão de ensinar". Já P8 registrou que julgava válida "[...] a formação continuada, havendo essa troca de ideias de forma mais abrangente, onde se pode tecer uma teia em relação aos conteúdos e atividades a serem trabalhadas interdisciplinarmente".

O protagonismo dos estudantes também foi observado: "Com certeza só vem a somar na qualidade de aprendizagem e desenvolvimento dos alunos que estiveram durante o processo à frente, interagindo, participando, criando, fazendo" (P3).

Além das contribuições da proposta formativa, solicitou-se, aos docentes, que apontassem tanto limitações como sugestões para seu aprimoramento. Enquanto P1 sugeriu que a formação ocorresse em horário de trabalho, para evitar jornada diária tripla, P8 reforçou o fato de, inicialmente, ter sido exaustivo transitar entre diferentes projetos que já eram desenvolvidos rotineiramente na escola.

Para evitar essa exaustão, a metodologia dos PCEs procura agrupar vários projetos trabalhados nas escolas de maneira ainda fragmentada. Dessa forma, o processo é gradativamente facilitado, por estimular um trabalho com foco em responsabilidades compartilhadas e na sinergia das iniciativas.

Os resultados, em geral, indicam que tanto a formação como o desenvolvimento do PCE favoreceram a transformação da prática pedagógica, ampliando a pertinência do ensino e a interação entre docentes, estudantes e comunidade. Nesse sentido, destaca-se que a formação fundamentou teoricamente ações práticas articuladas ao currículo escolar. Isso fez com que os estudantes não apenas demonstrassem o gosto por estarem na escola, mas também lhes despertou mais o interesse pela aprendizagem a partir de suas vivências, ampliando seus conhecimentos em relação ao mundo e valorizando seu lugar nesse processo.

\section{CONSIDERAÇÕES FINAIS}

Superar práticas pedagógicas motivadas por paradigmas de ensino e de aprendizagem descontextualizados, lineares e fragmentados não é uma tarefa simples. Para isso, compreende-se que oferecer propostas de formação aos docentes pode auxiliá-los nessa superação. Além disso, entende-se, também, que transladar uma prática pedagógica de um paradigma a outro significa, igualmente, transladar-se, tanto de modo pessoal como profissional, pois essas transformações demandam mudanças na forma de pensar, fazer, viver e conviver.

A ação extensionista, sistematizada neste artigo, comprometeu-se com esse processo ao promover uma intervenção em um contexto educacional específico. Assim, o seu objetivo foi contemplado, ou seja, avaliaram-se as potencialidades de um programa de formação transdisciplinar e ecoformador para transformar a prática pedagógica e atender às necessidades formativas dos docentes da EMEB Rodolfo Nickel.

Para elaborar um programa de formação que atendesse a tais demandas, importou abarcar experiências formativas que considerassem as especificidades de uma escola do campo. Nesse sentido, a análise de outros programas de formação que priorizaram a transdisciplinaridade e a ecoformação foi fundamental. Com isso, criaram-se possibilidades articuladas às demandas e às potencialidades da escola, dos profissionais, dos estudantes e da comunidade.

O uso de uma metodologia conectada à concepção pedagógica transdisciplinar e ecoformadora, no decorrer do desenvolvimento dos programas analisados, evidenciou 
possibilidades de transformação da prática pedagógica pretendida na pesquisa. Utilizar - tanto na formação dos docentes da EMEB Rodolfo Nickel como na prática desenvolvida em sala de aula durante o ano letivo - a metodologia do PCE permitiu que se transitasse, entre diferentes áreas do conhecimento, além e através delas. Isso favoreceu a religação de diferentes saberes, como os vinculados ao currículo escolar, os que faziam parte do cotidiano da comunidade, os que se tornaram imprescindíveis à solução de determinados problemas e os trabalhados por instituições externas, como a EPAGRI.

Na adaptação do PCE para a EMEB Rodolfo Nickel, foi determinante valorizar a flexibilidade das etapas formativas dos programas originais, pois, em seu desenvolvimento, junto à escola pesquisada, fez-se necessário alterar a sequência utilizada em outros contextos, em razão das condições dos docentes que participaram desta pesquisa. Nesse ajuste, foi desafiante o fato de que não haviam sido previstos, no calendário escolar, os encontros de formação durante o ano letivo, exceto em dois momentos pontuais. Por isso, o esforço e o comprometimento da equipe de docentes precisam ser valorizados, pois, para parte deles, a jornada nos dias de encontro era de praticamente 12 horas, distribuídas entre trabalho e formação.

Apesar de algumas faltas e do cansaço observado em determinados momentos, a participação da maior parte da equipe nas ocasiões previstas foi fundamental, pois, no decorrer dos encontros, elaborou-se o PCE. Nesses momentos, também, socializaram-se as inovações desenvolvidas em sala de aula durante sua aplicação, além de ser estimulado o aprofundamento teórico, ampliando a clareza sobre a relação entre a concepção pedagógica adotada e a prática efetivada.

Em relação ao perfil e às necessidades formativas dos docentes, foi decisiva a identificação dos desafios da escola, entre eles, priorizar o planejamento e as metodologias de ensino como temas para a formação e criar estratégias a fim de estimular o interesse dos estudantes. Tais demandas foram consideradas e satisfeitas no decorrer da intervenção, inclusive porque são condições integrantes das premissas do Programa de Formação-Ação em Escolas Criativas e da metodologia do PCE.

O desenvolvimento da proposta formativa priorizou também a realidade da escola do campo. Além disso, a iniciativa valorizou o trabalho desenvolvido pelos docentes antes do início do programa. Outra ação importante foi a escuta atenta dos docentes, dos estudantes e da gestora participante da ação extensionista, pois isso possibilitou a avaliação e o replanejamento do programa.

A percepção dos docentes, suas observações sobre as mudanças no planejamento, no interesse dos estudantes e na prática pedagógica demonstram o potencial do programa. Na análise geral, os pontos principais destacados foram a articulação teórico-prática, aproximando os conteúdos da realidade; a oportunidade de diálogo fundamentado na teoria, impulsionando uma nova visão sobre os processos de ensino e de aprendizagem; o estímulo ao protagonismo dos estudantes; e o trabalho colaborativo.

Vale observar, ainda, que a primeira Mostra do Conhecimento, realizada pela escola pesquisada, na etapa de polinização, difundiu o trabalho dos docentes e dos estudantes, favorecendo o reconhecimento de práticas transdisciplinares e ecoformadoras pela comunidade escolar interna e externa. Nesse processo, o PCE desenvolvido e socializado evidenciou conhecimentos que ultrapassaram as disciplinas.

A experiência e seus resultados proporcionaram a condecoração da escola durante a Jornada de Educação Alimentar e Nutricional do Fundo Nacional de Desenvolvimento da Educação (FNDE), 
quando the foram destinados um selo de participação e um certificado de menção honrosa. A premiação recebida deveu-se à conclusão de todas as etapas previstas na proposta de premiação e ao cumprimento de critérios como inovação, criatividade, continuação no andamento das atividades, envolvimento da família e conexão entre duas ou mais disciplinas.

Além disso, considerou-se a escola Destaque EPAGRI em Educação Socioambiental Márcia Mortari, reconhecimento recebido após os estudantes apresentarem um fragmento do PCE para outras escolas que concorriam à premiação. Para os docentes da EMEB Rodolfo Nickel, foi muito gratificante ver os estudantes superando ansiedades e medos enquanto compartilhavam, com segurança e autonomia, conhecimentos trabalhados ao longo do ano.

Quanto às limitações, destacam-se as dificuldades do calendário escolar, em que não foram previstas datas de formação durante o ano letivo, exceto no início do primeiro semestre e entre o primeiro e o segundo semestres. Além disso, a instabilidade quanto à manutenção do funcionamento futuro da escola gerou insegurança, especialmente na etapa de encerramento da proposta formativa. Ainda assim, todo o processo foi determinante para que a gestão pública tenha decidido, nas últimas semanas letivas, pela continuidade das atividades da escola do campo pesquisada.

Em relação a estudos futuros, sugere-se a inclusão dos familiares dos estudantes residentes na comunidade como sujeitos da pesquisa, pois se compreende que a escuta atenta dos pais e/ ou responsáveis pode contribuir ainda mais para um ensino transdisciplinar e ecoformador. Pela densidade das implicações, essa possibilidade não foi construída nesta pesquisa. Ainda assim, a participação efetiva das famílias foi determinante para os resultados alcançados.

\section{REFERÊNCIAS}

ABREU, T. R. As políticas sociais no neoliberalismo: expressões da luta de classes. In: JORNADA INTERNACIONAL EM POLÍTICAS PÚBLICAS, 8., 2017, São Luís. Anais [...]. São Luís: Universidade Federal do Maranhão, 2017, p. 1-5.

ASSOCIAÇÃO DOS MUNICÍPIOS DO ALTO VALE DO RIO DO PEIXE (AMARP). Diretriz Curricular da Educação Infantil. Videira: Secretaria Municipal de Educação, 2016. Disponível em: https://static.fecam.net.br/ uploads/834/arquivos/1708164_Diretriz_Curricular_Educacao_Infantil_ AMARP.pdf. Acesso em: 20 fev. 2018.

ARANHA, M. L. A. História da educação e da pedagogia: geral e Brasil. 3. ed. rev. e ampl. São Paulo: Moderna, 2006.

BOURDIEU, P. A miséria do mundo. 4. ed. Petrópolis: Vozes, 2001.

BRASIL. Ministério da Educação. Base Nacional Comum Curricular: educação é a base. Brasília: MEC, 2017. Disponível em: http://basenacionalcomum.mec.gov.br/images/BNCC_publicacao.pdf. Acesso em: 12 ago. 2017.

BRASIL. Ministério da Educação. Matrizes da Prova Brasil e do SAEB. Brasília-DF: MEC, 2008. Disponível em: http://portal.mec.gov.br/prova-brasil/matrizes-da-prova-brasil-e-do-saeb. Acesso em: 2 set. 2018.

BRASIL. Ministério da Educação. Secretaria de Educação Continuada, Alfabetização e Diversidade. Educação do Campo: diferenças mudando paradigmas. Brasília-DF: MEC, 2007. (Cadernos Secad2).

CARDOSO, J. P. et al. Psychosocial work-related factors and musculoskeletal pain among schoolteachers. Cadernos de Saúde Pública, n. 27, v. 8, p. 1498-506, 2011. Disponível em: http://www.scielo.br/scielo. 
php?script=sci_arttext\&pid=S0102-311X2011000800005. Acesso em: 27 nov. 2018.

GATTI, B. A.; BARRETO, E. S.; ANDRÉ, M. E. D. A. Políticas docentes no Brasil: um estado da arte. Brasília: UNESCO, 2011.

GONZÁLEZ VELASCO, J. M. Pensamiento religado: ligar para religar. La Paz: Prisa, 2018.

MAGNO, M. S. M. et al. Análise dos sintomas osteomusculares de professores do ensino fundamental em Matinhos (PR). Fisioterapia em Movimento, Curitiba, v. 4, n. 25, p. 785-94, 2012.

MORAES, M. C. Complexidade e educação: em busca de novos fundamentos teóricos e metodológicos. In: TORRE, S.; ZWIEREWICZ, M.; FURLANETTO, E. C. (Org.). Formação docente e pesquisa transdisciplinar: criar e inovar com outra consciência. Blumenau: Nova Letra, 2011. p. 17-46.

MORIN, E. Ensinar a viver: manifesto para mudar a educação. Tradução de Edgard de Assis Carvalho e Mariza Perassi Bosco. Porto Alegre: Sulina, 2015.

MORIN, E. A cabeça bem-feita: repensar a reforma, reformar o pensamento. Tradução de Eloá Jacobina. 16. ed. Rio de Janeiro: Bertrand Brasil, 2009.

NICOLESCU, B. Transdisciplinariedad: pasado, presente y futuro. In: MARTINEZ, A. C.; GALVANI, P. (Org.). Transdisciplinariedad y formación universitária: teorías y prácticas emergentes. Puerto Vallarta: CEUArkos, 2014. p. 45-90.

NICOLESCU, B. O Manifesto da transdisciplinaridade. Tradução de Lucia Pereira de Souza. 3. ed. São Paulo: TRIOM, 2005.

NÓVOA, A. Formação de professores e trabalho pedagógico. Lisboa: Educa, 2002.

NÓVOA, A. Professor se forma na escola. Nova Escola, São Paulo, maio 2001. Disponível em: https:// novaescola.org.br/conteudo/179/entrevista-formacao-antonio-novoa. Acesso em: 20 maio 2017.

NÓVOA, A. et al. (Org.). Formação de professores e profissão docente. Tradução de Graça Cunha, Cândida Hespanha, Conceição Afonso e José António Souza Tavares. Lisboa: Dom Quixote, 1992.

RIBEIRO, O. C.; MORAES, M. C. Criatividade em uma perspectiva transdisciplinar: rompendo crenças, mitos e concepções. Brasília: Liber Livro, 2014.

SANTOS, A. Complexidade e transdisciplinaridade em educação: cinco princípios para resgatar o elo perdido. In: SANTOS, A.; SOMMERMANN, A. (Org.). Complexidade e transdisciplinaridade: em busca da totalidade perdida. Porto Alegre: Sulina, 2009. p. 15-38.

SANTOS, A. O que é transdisciplinaridade. Rural Semanal, Rio de Janeiro, v. 28, n. 31, ago. 2005. Disponível em: http://www.ufrrj.br/leptrans/arquivos/O_QUE_e_TRANSDISCIPLINARIDADE.pdf. Acesso em: 15 mar. 2018.

SILVA, A. T. R. Ecoformação: reflexões para uma pedagogia ambiental, a partir de Rousseau, Morin e Pineau. Desenvolvimento e Meio Ambiente, Curitiba, n. 18, p. 95-104, jul./dez. 2008.

SILVA, D. Globalização, europeização e educação de adultos: reflexões sobre o programa novas oportunidades em Portugal. Revista Pedagógica, v. 32, n. 16, p. 141-68, 2014. Disponível em: https://bell. unochapeco.edu.br/revistas/index.php/pedagogica/article/view/2727/1551. Acesso em: 17 jun. 2018. 
TORRE, S. Movimento de Escolas Criativas: fazendo parte da história de formação e transformação. In: ZWIEREWICZ, M. Criatividade e inovação no Ensino Superior: experiências latino-americanas e europeias em foco. Blumenau: Nova Letra, 2013. p. 139-62.

TORRE, S. Projeto Inovar com outra consciência: transdisciplinaridade na sala de aula universitária. In: ZWIEREWICZ, M.; TORRE, S. (Org.). Uma escola para o século XXI: escolas criativas e resiliência na educação. Florianópolis: Insular, 2009. p. 193-206.

TORRE, S.; ZWIEREWICZ, M. Projetos criativos ecoformadores. In: ZWIEREWICZ, M.; TORRE, S. (Org.). Uma escola para o século XXI: escolas criativas e resiliência na educação. Florianópolis: Insular, 2009. p. 153-76.

UNIVERSIDADE ALTO VALE DO RIO DO PEIXE (UNIARP). Programa de Mestrado Profissional em Educação Básica. Caçador, 2018. Disponível em: https://www.uniarp.edu.br/home/ensino/ mestrado/mestrado-profissional-educacao-basica/. Acesso em: 5 jan. 2018.

UNIVERSIDADE DE BORÅS. Objectives and Visions. Borås: Universidade de Borås 2012.

ZWIEREWICZ, M. Programa de Formação-Ação em Escolas Criativas: matizes da pedagogia ecossistêmica na formação de docentes da Educação Básica. In: DITTRICH, M. G. et al. (Org.). Políticas Públicas na contemporaneidade: olhares cartográficos temáticos. Itajaí: Univali, 2017. p. 217-31.

ZWIEREWICZ, M. et al. Escolas Criativas: experiências transformadoras potencializadas na interação do Ensino Superior com a Educação Básica. Polyphonía, Goiânia, v. 27, n. 1, jan./jun. 2016.

ZWIEREWICZ, M. et al. Pedagogia ecossistêmica, transdisciplinaridade e ecoformação na gestão da Educação Básica: uma iniciativa da Secretaria de Educação de Paulo Lopes. In: SEMINÁRIO DA REDE INTERNACIONAL DE ESCOLAS CRIATIVAS - EDUCAÇÃO TRANSDISCIPLINAR: EMERGEM ESCOLAS CRIATIVAS E TRANSFORMADORAS, 3., 2017, Palmas. Anais [...]. Palmas: Universidade Federal do Tocantins, 2017. p. 1846-56.

\section{Sobre as autoras:}

Aline Lima da Rocha Almeida: Mestre em Educação Básica pela Universidade Alto Vale do Rio do Peixe (UNIARP). Coordenadora Pedagógica na Rede Municipal de Ensino de Caçador. E-mail: linerocha5@yahoo.com.br, Orcid: http://orcid.org/0000-0003-2367-7690

Marlene Zwierewicz: Doutora em Psicologia pela Universidade Federal de Santa Catarina (UFSC) e Doutora em Educação pela Universidade de Jaén (UJA) - Espanha. Coordenadora do Programa de Pós-Graduação de Ensino em Educação Básica (PPGEB) - Mestrado Profissional da Universidade Alto Vale do Rio do Peixe (UNIARP). Coordenadora, junto com Saturnino de la Torre da Red Internacional de Escuelas Creativas (RIEC). E-mail: marlenezwie@yahoo.com.br, Orcid: http://orcid.org/0000-0002-5840-1136 